\title{
Tuning of Controllers Developed for Oil Biodegradation Constructed Wetland
}

\author{
Deia Eldin Osman Hagahmed, Gurashi Abdallah Gasmelseed, and Siddig Eissa Ahmed
}

\begin{abstract}
Constructed Wetlands is a method of treatment of waste oil contents in water produced from oil fields. The method of treatment is found to be efficient and could reach greater than $\mathbf{9 0 \%}$ biodegradation if it is properly controlled. The case study proved continuous good performance. Besides, a need for good automatic control appears as other challenges facing sustaining the system performance with manual operation. In this work, the controlled variables are water level in lagoon No.1 and the oil content in the effluent from Reed Bed No.1. The primary controller through measurements of effluent oil content cascaded with the level controller of lagoon No.1 with subsequent changes in set point whenever required. A control strategy was developed and the relevant transfer functions were identified through transient material balance. The overall transfer functions were calculated and characteristic equations for both closed and open loops were determined. From those transfer functions, the systems controllers were subjected to tuning techniques, and simulation response using MATLAB software.
\end{abstract}

Index Terms-Constructed wetlands, tuning, controller, produced water.

\section{INTRODUCTION}

Produced water is the water that co-produced water from the oil and gas industry. Globally, it represents a major concern in the oil and gas industry; as well as it accounts for a significant waste stream in the United States. For some estimates, produced water volume in the United States is most likely higher than 14 to 18 billion barrels [1].

Produces water can be contaminated by oil exploration and production operations, tank farms, underground storage tanks leakage and refineries have become a concern to the oil and gas industry.

Produced and wastewaters represent the largest volume waste stream in the exploration and production of oil.

Most of the traditional treatment technologies used by the oil industry such as hydro-cyclones, coalescence, flotation, centrifuges and various separators are not efficient concerning the removal of dissolved organic components; including aromatics in the dissolved water phase [2], [3].

Treatment and disposal of such large volume is of great concern to the operator and the environment. Wastewaters from the oil industry contain aromatic hydrocarbons such as benzene, toluene, ethyl benzene and xylene (ortho, meta and para isomers), which are highly soluble, neurotoxic and cause cancer [4].

Oil exploration in Sudan started in 1959, but the first major

Manuscript received May 5, 2014; revised August 21, 2014.

Deia Eldin Hagahmed is with University of Science and Technology, Khartoum, Sudan (e-mail: deiahagahmed@yahoo.com). find was only made in 1980 by the US Company Chevron (now Chevron-Texaco). United Nation Environmental Programme mentioned that the single most significant environmental issue for crude oil production facilities in Sudan is: the disposal of produced water. As per the report of the UNEP, the Heglig facility alone currently generates over ten million cubic meters of produced water annually. Full production of the central Sudan fields in ten-year' time may yield five to twenty times that amount. Appropriate treatment and disposal options exist for produced water, but they can be costly [5].

Since 1995, journal articles and symposia proceedings indicate the petroleum industry's interest in using constructed wetlands to manage process wastewater and storm water at a variety of installations including refineries, oil and gas wells, and pumping stations [6].

Constructed wetland technology is environmentally friendly and less expensive than other physical-chemical methods, because it involves natural processes resulting in the efficient conversion of hazardous compounds [7].

Some scientist emphasized that: the single most significant environmental issue for crude oil production facilities in Sudan the disposal of produced water [8].

As it is the largest single associated waste product in crude oil production, it is a great challenge for oil companies to find a best method to dispose produced water in environmentally friendly and optimum economic conditions [9]. Some recited Constructed Wetlands as a promising tool in this endeavor because it can provide an effective approach for managing and preserving the environment

Constructed Wetlands have the potential of removing organics such as aromatic components in the dissolved water phase and inorganic compounds in wastewater [10].

Constructed wetlands offer the benefits of natural wetlands, but can be "custom made" to meet the treatment and construction needs of each individual site. Despite the increasing popularity, the effectiveness, environmental friendliness and positive economics of constructed treatment wetlands, the application of this novel wastewater treatment technology is still rare in the petroleum industry. Wetland systems reduce many contaminants, including organics (BOD, COD), suspended solids, nitrogen, phosphorus, trace metals, and pathogens [11].

In 2004, a Treatment Constructed Wetlands pilot system was made at Heglig. The system was designed for receiving $16,000 \mathrm{~m}^{3}$ of water per day. Treatment capabilities and toxicology were extensively studied for 18 months by the Sudanese Commission for The Environment and Safety. Despite the final capacity increasing to over $40,000 \mathrm{~m}^{3}$ of water per day during this time, the Commission judged that the system was approved as the best environmentally friendly 
acceptable techniques for removal of oil contamination from produced waters. According to Greater Nile Operating Company (GNPOC) 2008 annual report, treatment consistently achieved the required Sudanese Standard for Discharge to the environment, with combined free and dissolved hydrocarbon contamination levels below detectable levels for almost all outlet samples.

As in our case study, the treatment constructed wetlands systems have ensured that Heglig achieve compliance for discharge of vast quantities of treated water to surface waters, but also allowed local agencies to establish over $40 \mathrm{~km}^{2}$ of sustainable forestry, providing value crops and employment to the local community. In addition, the treatment systems have consistently proved to have no toxicological effect on the local environment, rather providing areas where biodiversity increases in the treatment sites. As well as re-establishing wetland habitats in Sub-Saharan Africa, the systems host resident and migratory populations of four species that are on red list of threatened species [12].

There is no control system for Heglig oil facility. Although the usage of Constructed Wetlands has proved efficiency in biological treatment of the Produced Water and, successfully, delivered appropriate effluent for the purpose of Forestry irrigation, but still there are some challenges that facing the long term operation of the Constructed Wetlands, e.g. the continuous increasing in the volume of influent, the fluctuations of levels of pollutants in the influent, the operation cost, etc.

In most of cases around the world, the operation of Constructed Wetlands is still manually controlled; while other conventional treatment units and systems going for automatic controlling. This step will sustain the oil field production through continuous discharging of generated Produced Water.

Adequate automatic control constructed wetlands for Produced Water treatment would help in:

- Maintaining smoothness of Operation, i.e. preventing system over flow, water stagnation, and plant over draught.

- Minimizing cost of operation by reducing human interference.

- Maintaining safety of labor- by minimizing contact between human and toxic $\backslash$ harmful chemicals.

- Meeting last user (Re-user) specifications-final effluent to be in the right amount and specific quality.

- Maintaining the most optimum condition for the Hydrocarbon degradation in influent.

- Complying with local and international environment regulations for the discharge of treated water to open environment or for reuse option.

To enhance hydrocarbon removal in Constructed Wetlands, there is a need to design and develop a control system and analyze different inlets and outlet parameters especially: water level, pH, Electrical Conductivity, Dissolved Oxygen, and nutrients. Those parameters, usually, have proven their significant influence on the efficiency of the processes occurred in the Constructed Wetlands and in the same time they are controllable and easy to be measured online. This study is aiming to develop a control strategy and system for Hydrocarbon removal Constructed Wetland and to analyze the developed control system's performance and stability.
The key to maintain the efficiency of the constructed wetland is the water level across the whole system. The best control to the system to optimize the biodegradation of the hydrocarbon in the system by preventing the whole system from over flooding through controlling the input: volume of water. Therefore level Controller is the best controller which will be studied and investigated to keep the water level in the lagoons and reed beds within the acceptable values. This, eventually, will lead to give the plants the suitable time for biodegradation and prolong the travelling time of water through the system in order to enhance evaporation, trans-evaporation, transpiration, volatilization, and all removal mechanisms. On the other hand, the constructed wetland system might be exposed to different situation where water balance would be essential for the viability of plants and its remediation capability; such as heavy rain (precipitation), Floods (plants over hydration), High temperature (plant draughts), etc.

\section{MATERIALS AND METHODS}

Polluted Produced water flows from the Heglig Central Processing Facility (CPF) to the two sequential evaporation ponds, and then pumped along a pipeline to the first receiving Storage Lagoons (SL). The produced water at the end of the pipeline is discharged into a small chamber (delivery basin) within the first lagoon and then cascades over the top of the chamber into the lagoon proper. The series of Storage Lagoons (SL); SL1 to SL6 are followed by Reed Bed (RB); RB6 to RB1.

Water balance of the first lagoon or system intake/entrance is essential to manipulate all other parameters of the system.

In our case study the water pass all lagoon first then reed beds and canals before discharged; which mean the appropriate and good control of the inlet is the only method to maintain the water in optimum level throughout the whole system.

The Reed Beds are planted with Phragmites australis. The water exiting these lagoons flows under gravity into a balanced distribution canal and then into a much larger ploughed section assigned to forestry and wetland species. The flow path for the produced water is from SL1 to SL6, whiles the flow from Storage Lagoons into the Reed Beds; RB6 to RB1 can take several combinations of flow pattern. This is because the system is designed to incorporate various flow patterns whether on series, parallel or a combination of both.

From Interviews and observations the dominant pattern of the case study operation is on series, and this pattern is the one which will be used in the research. Also, transmission of the produced water from one lagoon to the next is by gravity flow through a bottom gate valve.

In our proposed control system, the controlled variables are to be the oil in water content in the influent and effluent of the case study. The oil in water content will be cascaded with the inflow of polluted water entering the system. A cascade control system is a multiple-loop system where the primary variable is controlled by adjusting the set point of a related secondary variable controller. The secondary variable, then, affects the primary variable through the process. See Fig. 1. 


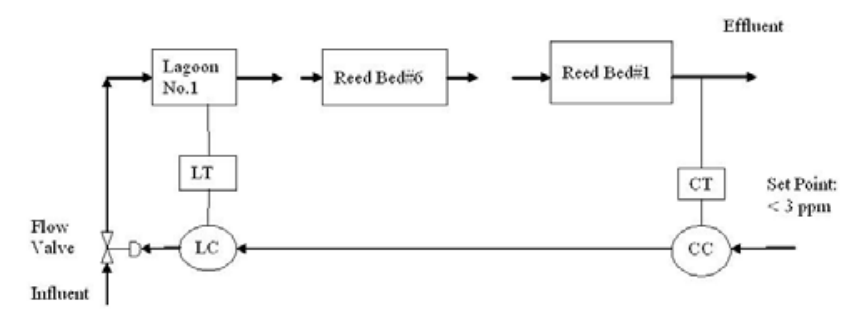

Fig. 1. Physical diagram for a proposed cascade control system for oil biodegradation in a Heglig1 constructed wetland. LT: Level Transmitter, CT: concentration transmitter, LC: Level Controller, CC: concentration controller.

In our case, we suggest applying cascade control system; while selecting the BOD concentration sensor as measuring element for the effluent as the primary variable and level of water in Storage Lagoon No. 1 (SL1) as a secondary controlled variable. Both are subjects to external disturbances. A block diagram for the system is shown in Fig. 2. From many control texts [13], we selected four methods to design and tune of our proposed controller. Proportion action repeats the input signal and produces a continuous action.

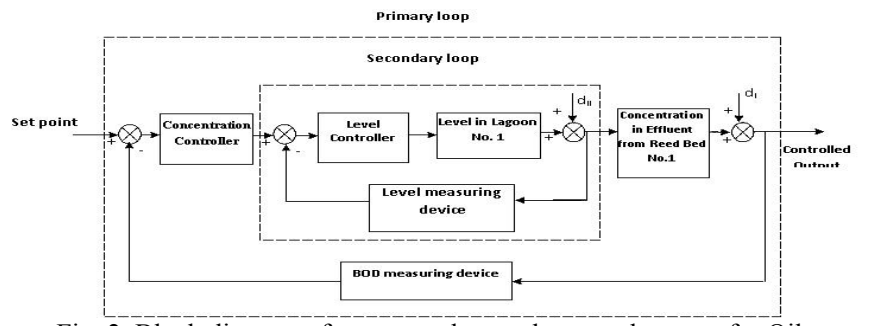

Fig. 2. Block diagram of a proposed cascade control system for Oil biodegradation in a constructed wetland. $d_{I}$ and $d_{I I}$ are disturbance one and two, respectively.

The gain $K_{c}$ will be positive if an increase in the input variable requires an increase in the output variable (direct-acting control), and it will be negative if an increase in the input variable requires a decrease in the output variable (reverse-acting control). Proportional action decreases the rising time making the response faster, but it causes instability by the overshooting (offset).

The controller is the active element that is receives the information from the measurements and takes appropriate control actions to adjust the value of the manipulated variables taking the best response of the process using different controller laws. In order to be able to design a good controller, it must be tuned to the system. This tuning synchronizes the controller with the controlled variable, thus allowing the process to be kept at it is.

\section{A. Bode Diagram Method}

Bode plots are common graphical representation of Amplitude Ratio (AR) and Frequency $(\boldsymbol{\theta})$ functions. A Bode Plot consists of two graphs: $\log A R$ vs. $\log \boldsymbol{\omega}$ and $\boldsymbol{\theta}$ vs. $\log$ $\boldsymbol{\omega}$. To determine the ultimate gain $\left(K_{u}\right)$ and ultimate period $\left(P_{u}\right)$, we have to plot the Open loop Transfer Function first. So, we can get the $\boldsymbol{\omega}_{\text {co }}$ and AR from the plot. Then, by equating the AR with one at the cross-over frequency, we can calculate the $K_{u} \& P_{u}$.

\section{B. Root-Locus Plots Tuning Method}

It is used to determine the ultimate gain and ultimate period from the root locus. This can be realized by the following steps:
- Drawing the root locus for the close loop Transfer Function.

- Putting the Characteristic Equation in imaginary roots formula then equating it with zero.

- Equating each imaginary part and real part with zero.

- Calculate Ultimate Gain and Ultimate Period

\section{Ziegler-Nicholas (Z-N) Tuning Method}

Ziegler-Nicholas is one of tuning techniques. It goes through the following steps:

- Set up the system with proportional control only.

- Make a set point step test and observe the response.

- Evaluate the period of the constant oscillation; this period is called the ultimate period $\left(P_{u}\right)$ and the gain is the ultimate gain $\left(K_{u}\right)$.

- Calculate the parameters according to the following formulas:

\section{RESUlTS AND DISCUSSION}

\section{A. Transfer Functions for Primary Control Loop}

\section{1) Biodegradation process}

As per our case study type; i.e. Free Water Surface Constructed Wetlands system, we used equation suggested by Reed, Crites and Middlebrooks [14]:

$$
C_{0} / C_{i}=\exp \left(-K_{t} \cdot t\right)
$$

where:

$C_{\mathrm{o}}$ : outlet concentration of pollutant $(\mathrm{mg} / \mathrm{l}), C_{i}$ : inlet concentration of pollutant $(\mathrm{mg} / \mathrm{l}), K_{t}$ : constant temperature dependant (per day), t: hydraulic retention time (day).

As per the above equation condition and design of the case study [15], 5 to 21 days is enough for "Free Water Surface System" to more than $90 \%$ biodegradation. That means the value of $K_{t}$ will be varying between 0.001 to $0.005 /$ day $(0.00004$ to $0.002 / \mathrm{hr})$.

We take the greatest value to $K_{t}$ as the area of the reed beds in our case study is huge and temperature average is considered high throughout the year.

Therefore, the process transfer function $\left(G_{B}\right)$ for Oil Content biodegradation in water entering Reed Bed \#6 is given by taking La Place for equation (1):

$$
G_{B}(s)=\frac{C_{0}(s)}{C_{i}(s)}=\frac{1}{s+0.002}=\frac{500}{500 s+1}
$$

\section{B. Secondary Control Loop Transfer Functions}

\section{1) Liquid level process}

We can express the relationship between time of process $(\boldsymbol{\tau})$ and the level of water $(h)$ inside the lagoon as follows:

$$
\tau \frac{d \hat{h}}{d t}+h=q^{\wedge} \cdot R_{S L 1}
$$

where

Difference in water level, $q^{\wedge}$ : Difference in Inflow,

$R_{S L 1}$ : Storage Lagoon No.1 Outlet Valve Resistance

To get the final Process Transfer Function $G_{L}(s)$, we should take Laplace transformation for the above equation 
and we will get:

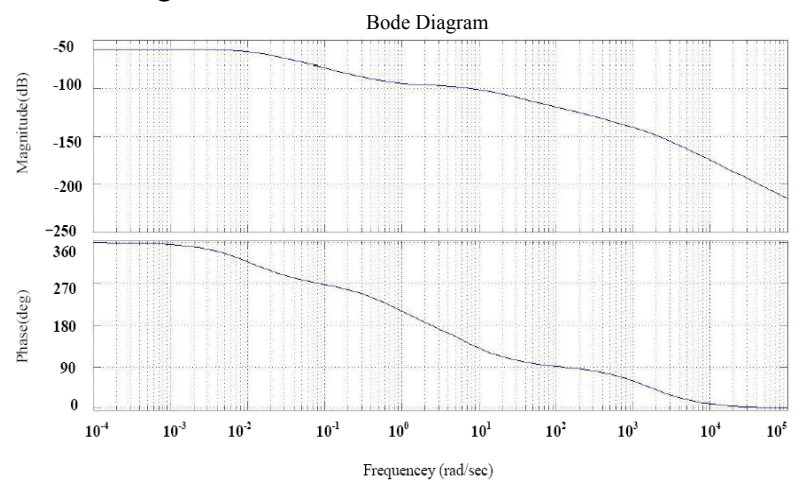

Fig. 3. Bode plot of the secondary loop control system.

$$
G_{L}(s)=\frac{H(s)}{Q(s)}=\frac{R_{S L 1}}{\tau s+1}
$$

The process transfer function was determined for the Constructed Wetland Inflow as follows:

$$
G_{L}(s)=\frac{0.001}{87.45 s+1}
$$

Since the water entering the system is transferred through pump and pipe line, so there is a dead time must be estimated and the equation (5) will be:

$$
G_{L}(s)=\frac{0.001}{87.45 \mathrm{~s}+1} e^{-0.27}
$$

With applying Padé approximation, we can get the following equation:

$$
G_{L}(s)=\frac{-0.00135 \mathrm{~s}+0.001}{\left(11.81 \mathrm{~s}^{2}+87.585 \mathrm{~s}+1\right)}
$$

\section{2) Level sensor}

A pressure sensor will be employed to compute the liquid level. Pressure differences cause small displacements of the sensing diaphragm. Capacitor plates on both sides of the diaphragm detect the position of the sensing. The differential capacitance between the sensing diaphragm and the capacitor plates is converted into DC voltage [16].

So, the level measurement transfer function was determined as follows:

$$
G_{m}(s)=\frac{0.125}{0.0000001 \mathrm{~s}^{2}+0.0003 \mathrm{~s}+1}
$$

\section{3) Flow valve}

For a normal valve, a first order transfer function can be used:

$$
G_{v}=\frac{K_{v}}{\tau_{v} s+1}
$$

We suggest a control valve of the case study, as per Gopal and Richard [17] recommendation about such similar case. From the case study system configuration, $G_{v}(s)$, we obtain:

$$
G_{v}=\frac{7.5}{0.0003 s+1}
$$

4) Overall transfer function:

$$
G_{\text {Sec }}=\frac{K_{c 2}(-0.0101 s+0.0075)}{\left(0.0071 s^{3}+11.8626 s^{2}+\left(87.5836-0.0013 K_{c 2}\right) s+0.001 K_{c 2}+1\right)}
$$

\section{Controller Offset}

1) For secondary controller

The Offset of a controller is calculated mathematically by deducting output transfer function $C_{\mathrm{o}}(s)$ for infinity value from Input transfer function $R(s)$ which is ideally to be unity.

$$
\text { Offset }=C_{\mathrm{o}}(\infty)-C_{\mathrm{o}}(\text { ideal })=C_{\mathrm{o}}(\infty)-1
$$

While:

$$
C_{\infty}=\lim _{S=0}\left(S . C_{(s)}\right)
$$

So; the offset for the above secondary overall transfer equation (11) can be calculated as following:

$$
C_{\infty}=\frac{0.0075 K_{C 2}}{1+0.001 K_{c 2}}
$$

$$
\therefore \text { Offset }=\frac{0.0075 K_{c 2}}{1+0.001 K_{c 2}}-1
$$

Or

$$
\text { Offset }=\frac{0.0065 K_{c 2}-1}{1+0.001 K_{c 2}}
$$

\section{2) For primary controller}

Similar to the above methodology, the offset for the primary controllers can be developed after obtaining the value of Secondary controller gain and then apply it in the overall system transfer equation.

\section{Secondary Controller Tuning \\ 1) Bode plot method}

We make the equation (11) or the characteristic equation equals to zero, so:

$$
1+\frac{\mathrm{K}_{\mathrm{C} 2}(-0.0013 \mathrm{~s}+0.001)}{\left(0.0071 \mathrm{~s}^{3}+11.8626 \mathrm{~s}^{2}+87.5836 \mathrm{~s}+1\right)}=0
$$

The Bode plot of the secondary loop control system transfer function is plotted using MATLAB as shown in Fig. 3 below:

As we see from the above graph, they system doesn't cross the $-180^{\circ}$ phase; so the system is stable for very high value of gain, but this method cannot be used for the case.

\section{2) Root locus method}

Root locus of the secondary loop control system transfer function was plotted using MATLAB. Reading from the generated graph, we find frequency $(\boldsymbol{\omega})$ is equal to 0.1296 $\mathrm{rad} / \mathrm{sec}$. Then, we can determine the ultimate gain from the root locus. This is obtained by putting the characteristic equation, in imaginary roots formula then equating it with zero. So, if we apply that: $s=i \boldsymbol{\omega}$, we will get the characteristic equation in this format:

$$
\begin{array}{r}
0.0071 i^{3} \omega^{3}+11.8626 i^{2} \omega^{2}+\left(87.5836-0.0013 K_{c 2}\right) i \omega+0.001 K_{c 2}+1=0(18) \\
-0.0071 \mathrm{i} \omega^{3}-11.8626 \omega^{2}+\left(87.5836-0.0013 \mathrm{~K}_{\mathrm{c}}\right) i \omega+0.001 \mathrm{~K}_{\mathrm{c}}+1=0
\end{array}
$$

At critical stage the root of the equation will equal zero and the gain $\left(K_{c 2}\right)$ will be ultimate $\left(K_{u 2}\right)$. Equating the imaginary part in the equation with zero, we get: 


$$
-0.0071 \omega^{3}+\left(87.5836-0.0013 K_{u 2}\right) \omega=0
$$

Substituting with $\omega=0.1296 \mathrm{rad} / \mathrm{sec}$, we get:

$$
\therefore K_{u 2}=67,372, K_{c 2}=33,686
$$

Offset will be calculated using equation (16):

$$
\text { Offset }=\frac{0.0065 \times 33,686-1}{1+0.001 \times 33,686}=6.2
$$

\section{3) Ziegler-Nicholas (Z-N) tuning method}

Using Simulink feature in MATLAB Software, we sat up the system with proportional control only. See the following Fig. 4:

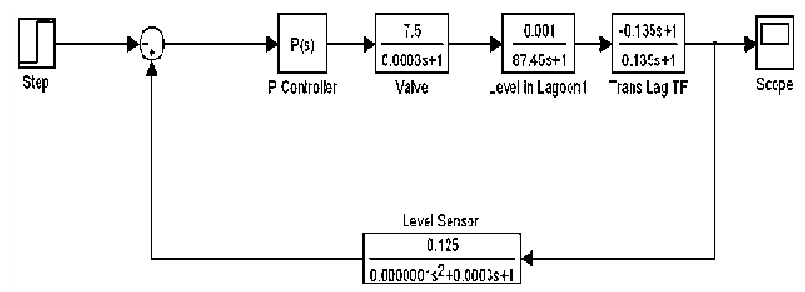

Fig. 4. Simulink Block Diagram for the secondary loop control system.

We made a set point step test, assumed many values for controller gain $\left(\mathrm{K}_{\mathrm{c} 2}\right)$, and then we observed the response. To be close to the same conditions of the previous tuning methods, we eliminated the small coefficients of the measuring element and considered it Unity Transfer Function. See the following Fig. 5:

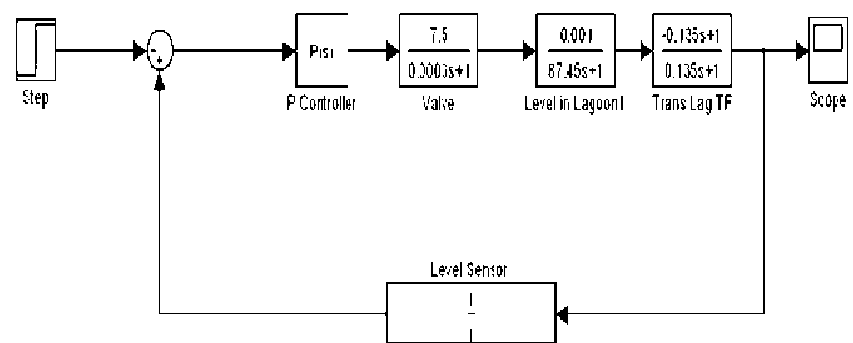

Fig. 5. Modified Simulink block diagram for the secondary loop control system.

We entered different values for gain and we found a constant oscillation; when $K=-71,800=K_{u 2}$ (Ultimate Gain). See the following Fig. 6:

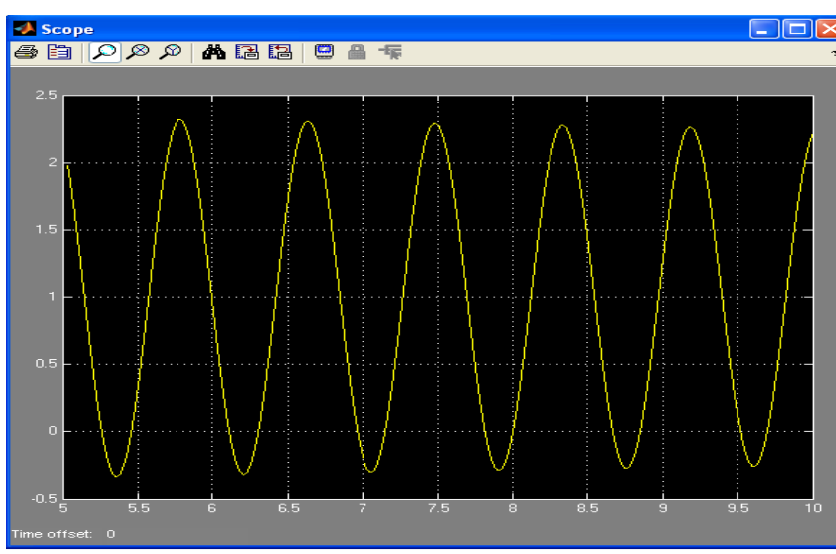

Fig. 6. Simulink secondary loop control system oscillation.

According to Table I, $K_{c 2}=0.5 K_{u 2}=-35,900$. Offset as calculated and found equal to 6.3 .

TABLE I: ZIEGLER-NiCHOLAS ClOSED LOOP RELEVANT CONTROLLER PARAMETERS

\begin{tabular}{|c|l|l|l|}
\hline $\begin{array}{l}\text { Controller } \\
\text { type }\end{array}$ & $\begin{array}{l}\text { Gain } \\
K_{c}\end{array}$ & $\begin{array}{l}\text { Integral time } \\
\boldsymbol{\tau}_{i}\end{array}$ & Derivative time \\
\hline $\mathrm{P}$ & $0.5 k_{u}$ & - & - \\
\hline $\mathrm{PI}$ & $0.45 K_{u}$ & $P_{u} / 1.2$ & - \\
\hline $\mathrm{PID}$ & $0.6 K_{u}$ & $P_{u} / 2$ & $P_{u} / 8$ \\
\hline
\end{tabular}

\section{E. Primary Controller Tuning}

For our design, we selected a value for the Secondary Controller Gain $\left(K_{c 2}\right)$ as: 33,700, so; the Overall Transfer Function can be represented as below:

$G_{\text {Overall }}$
$=\frac{K_{c 1}(-22747.5 \mathrm{~s}+16850)}{\left(5905 s^{3}+43804 s^{2}+\left(588-22747.5 K_{c 1}\right) \mathrm{s}+1+16850 K_{c 1}\right)}$

\section{1) Bode Plot Method}

We make equation (21) or the characteristic equation equals to zero, as following:

$$
1+K_{c 1} \frac{(-22,747.5 s+16,850)}{\left(5,905 s^{3}+43,804 s^{2}+588 s+1\right)}=0
$$

The Bode plot of the primary loop control system transfer function is plotted using MATLAB as shown in Fig. 7 below:

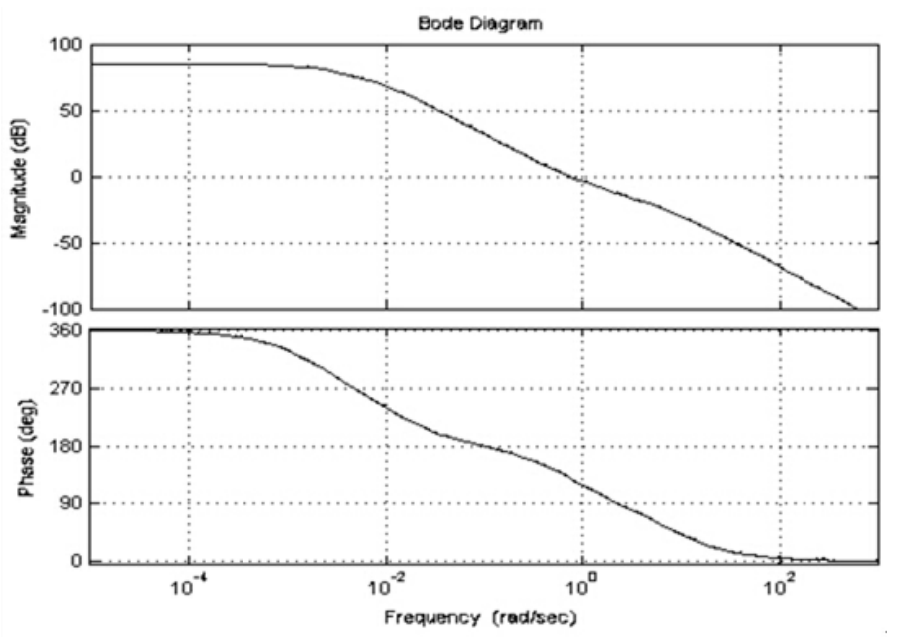

Fig. 7. Bode plot of the cascade system.

As we see from the above graph, they system doesn't cross the $-180^{\circ}$ phase; so the system is stable for very high value of gain, but this method cannot be used for the case.

\section{2) Root locus method}

Root locus of the primary loop control system transfer function was plotted using MATLAB. Reading from the generated graph, we find frequency $(\boldsymbol{\omega})$ is equal to 0.0853 $\mathrm{rad} / \mathrm{sec}$.

Similar as described above in critical stage the root of the equation will equal zero and equating the imaginary part in the equation with zero, we get:

$$
-5905 \omega^{3}+\left(588-22747.5 K_{u 1}\right) \omega=0
$$

Substituting $\boldsymbol{\omega}$ with 0.0853 , we get: 


$$
\therefore K_{u 1}=0.0008, K_{c 1}=0.0004
$$

Offset can be calculated as following:

$$
\begin{aligned}
C_{\infty} & =\frac{16850 K_{C 1}}{1+16850 K_{c 1}} \\
\text { Offset } & =\frac{16850 K_{c 1}}{1+16850 K_{C 1}}-1
\end{aligned}
$$

or

$$
\text { Offset }=\frac{16850 K_{c 1}-1}{16850 K_{c 1}+1}=\frac{16850 \times 0.0004-1}{16850 \times 0.0004+1}=0.7
$$

\section{3) Ziegler-nicholas (Z-N) tuning method}

The cascade control system in numerical transfer functions is shown in the following block diagram:

Using Simulink feature in MATLAB Software, we applied Ziegler-Nicholas tuning method technique. We sat up the primary controller on proportional only. Then, we made a set point step test, assumed many values for controller gain $\left(K_{c 1}\right)$. We observed the response. After different values for gain entered, we found a constant oscillation; when $K=-3.75=$ $K_{u 1}$ (Ultimate Gain).

According to Ziegler-Nicholas Closed Loop Method: $K_{C 2}=$ $0.5 K_{u 2}=-1.875$. Offset as calculated and found equal to 1 .

\section{F. Unit Step Test}

Taking the lowest offset into calculation of overall transfer function with a primary controller gain equal to 0.004 and secondary controller gain equal to 33,700 , equation $(21)$ or the overall transfer function obtained will be as follows:

$$
G_{\text {Overall }}(s)=\frac{(-9.1 s+6.7)}{\left(5,905 s^{3}+43,804 s^{2}+578.9 s+7.74\right)}
$$

The continuous step response for this overall transfer function is as in the following Fig. 8:

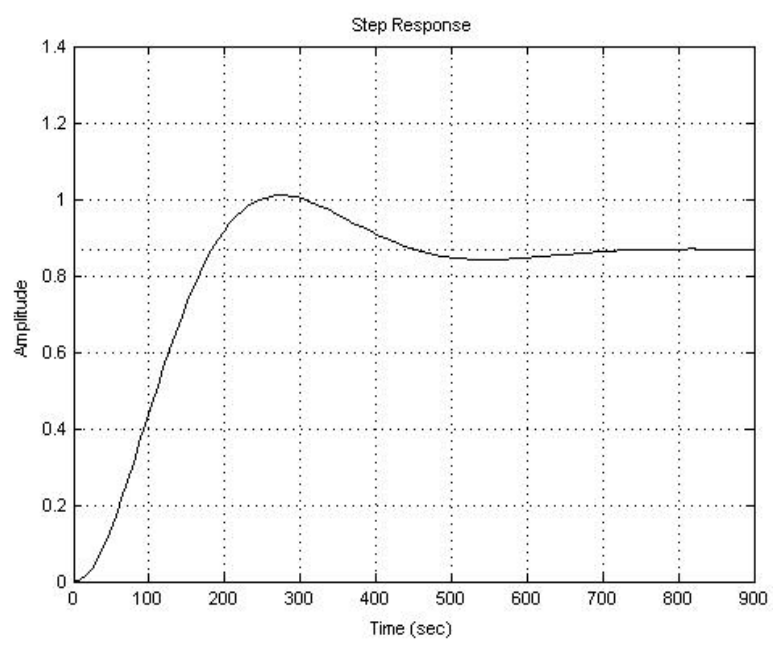

Fig. 8. Continuous response due to step change for overall cascade system.

The above graph shows the response of the cascaded control system is smooth and system go into stability in acceptable manner; which indicates that the two controllers are well tuned.

\section{CONCLUSIONS}

It is known that petroleum industry produces much of water contaminated with oil. The treatment of this wastewater is expensive and at the same time it does not bring any income. However, constructed wetlands technology is cheap, friendly to the environment. Constructed wetlands have the potentiality of removing organic and inorganic in wastewater. In constructed wetland methods, it requires a control strategy with précised controller specification so as to, tightly, keep the units not to flood and have time to conform to the specifications required.

This research paper studied a developed feedback control system for the constructed wetland used in Heglig Oil facility for treatment of wastewater accompanying oil production using MATLAB software. In this paper two controllers were developed and tuned using MATLAB software with various techniques. Results of different techniques were very near; which indicate to the precision of the designed controllers.

\section{ACKNOWLEDGMENTS}

We would like to thank Sudanese Ministry of Petroleum, Greater Nile Operating Company, Petrodar Operating Company, Mrs. Samah Sirelkahatim Ahmed and Oceans ESU Limited for their cooperation and support.

\section{REFERENCES}

[1] C. E. Clark and J. A. Veil. (2009). Produced Water Volumes and Management Practices in the United States - report prepared for U.S. Department of Energy, Office of Fossil Energy, National Energy Technology Laboratory. [Online]. Available: http://www.netl.doe.gov/technologies/coalpower/ewr/water/pdfs/anl\% 20 produced $\% 20$ water\%20volumes\%20sep09.pdf.

[2] A. Descousse, K. Monig, and K. Voldum. Evaluation Study of Various Produced Water Treatment Technologies to Remove Dissolved Aromatic Components. [Online]. Available: http://www.spe.org/elibrary.

[3] Aromatics in Produced Water: Occurrence, Fate and Effects, and Treatment. [Online]. Available: http://www.ogp.org.uk/pubs/324.pdf.

[4] T. Hiegel, "Analysis of pilot scale constructed wetland treatment of petroleum contaminated groundwater," M.S. thesis, Department of Civil Engineering, University of Wyoming, Laramie, Wyoming, U.S.A., 2004.

[5] Post-Conflict Environmental Assessment. [Online]. Available: http://postconflict.unep.ch/publications/UNEP_Sudan_synthesis_E.pd f.

[6] S. H. Ye, L. C. Huang, Y. O. Li, M. Ding, Y. Y. Hu, and D. W. Ding, "Investigation on bioremediation of oil-polluted wetland at Liaodong Bay in northeast China," Applied Microbiology and Biotechnology, vol. 71, no. 4, pp. 543-548, 2006.

[7] R. L. Knight, R. H. Kadlec, and H. M. Ohlendorf, "The use of treatment wetlands for petroleum industry effluents," Environmental Science and Technology, vol. 33, no. 7, pp. 973-980, 1999.

[8] S. I. Mohammed, "Environmental governance and legal framework," presented at First Seminar on: Environmental \& Safety Concerns \& Management in Sudan Upstream Oil Industry, Ministry of Petroleum, Khartoum, Sudan, 2008.

[9] S. E. Ahmed, "Sudan upstream oil industry: an overview of environmental issues and management approaches," presented at First Seminar on: Environmental \& Safety Concerns \& Management in Sudan Upstream Oil Industry, Ministry of Petroleum, Khartoum, Sudan, 2008.

[10] S. D. Wallace and R. L. Knight, "Small-scale constructed treatment systems: feasibility, design criteria, and O \& M requirements. Final report, Project 01-CTS-5," Water Environment Research Foundation, Alexandria, Virginia, U.S.A., 2006.

[11] P. E. Eke, "Hydrocarbon removal with constructed wetlands," Ph.D Thesis, Department of Civil Engineering, University of Edinburgh, Edinburgh, United Kingdom, 2008. 
[12] Hydrocarbon Removal from Oilfield Produced Water: Contaminated Water Solutions Water Case Study. [Online]. Available: http://www.oceans-esu.co.uk/wp-content/uploads/2012/02/Heglig-Hy drocarbon-Removal-from-Oilfield-Produced-Water.pdf

[13] M. E. Abu Goukh, Controlling Techniques and system Stability, Department of Chemical Engineering, University of Khartoum Press, Khartoum, 2003.

[14] G. A. Gasmelseed, A Text Book of Chemical Engineering, Process Control, G-Town Book Store and Press, Khartoum, 2010, pp. 103-146.

[15] S. C. Reed, E. J. Middlebrooks, and R. W. Crites, Natural Systems for Waste Management \& Treatment, McGraw Hill, New York, 1988.

[16] Greater Nile Operating Company (GNPOC) Heglig1 Bioremediation Project Design- Annual Report, Report No.: 070304, Heglig Oil Field, West Kordofaan, GNPOC Internal Reports, Oceans ESU, Khartoum, Sudan, 2003.

[17] S. K. Singh, Computer-Aided Process Control, Prentice-Hall of India private limited, New Delhi, India - 110 001, 2005, pp. 190-244.

[18] M. Gopal and F. V. Richard, Control Systems, Principles and Design, Leasing of Industrial Equipment, Tata Mc Graw-Hill Publishing Company Limited, 7 West Patel Nagar, New Delhi, India, 2008, pp. 155.

[19] D. O. Hagahmed, G. A. Gasmelseed, and S. E. Ahmed. (January 2014). Multiple Loops Control of Oil Biodegradation in Constructed Wetlands. Journal of Applied and Industrial Sciences. 2 (1). pp. 6-13, [Online]. Available: http://researchpub.org/journal/jais/number/vol2-no1/vol2-no1-1.pdf

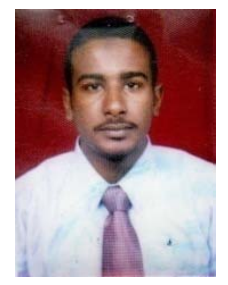

Deia Eldin Osman Hagahmed is a sudanese chemical and environmental engineer. He received his bachelor in science (honors) chemical Engineering from University of Khartoum, Khartoum, Sudan, 1999 and He received his master in business administration - specialization: project management from University of Science and Technology, Khartoum, Sudan, 2012.

$\mathrm{He}$ is an environmental engineering $\mathrm{PhD}$ student in UNESCO chair in water resources, Khartoum, Sudan, now.

Deia is working in Petrodar Operating Company for more than 10 years, and he is considered a professional environmental engineering solution for Oil and Gas industry.

Mr. Hagahmed is an associate member in Institute of Environmental Management and Assessment (IEMA), UK, National Examination Board for Occupational Health and Safety (NEBOSH), UK, Sudan Engineering Council, Sudanese Engineering Society, Sudanese Environment Conservation Society.

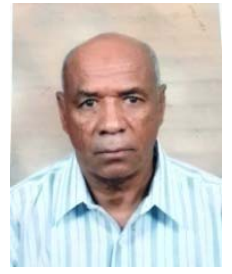

Gurashi Abdalla Gasmelseed is the chairman of industrial chemicals committee in the sudanese specifications and metrology corporation. He was born in Khartoum in 1975 . He received his bachelor in science chemical engineering from University of Khartoum, Khartoum, Sudan, in 1971. He received his diploma in leather technology from Northampton College of Technology, UK in 1974. He received his master of science in chemical engineering from University of Khartoum, Khartoum, Sudan in 1978 and He received his Ph.D in chemical engineering from Aston University, Birmingham, UK in 1985.

Gurashi is a professor in chemical engineering and teaching now in many Sudanese Universities. He is a professional in process modeling, simulation and control. Moreover, he as a supervised on more than $50 \mathrm{M}$. Sc thesis, and more than 14 Ph.D thesis. He published more than 22 research papers and he is author and co-author for many books and text book, e.g. A Text Book of Chemical Engineering, Process Control, and Khartoum, Sudan: G. A. Gasmelseed, 2010.

Mr. Gasmelseed was a secretary of research funding committee in University of Kuwait (1986-1990), as a secretary of research in Graduate College of Higher Education and he is a Research, University of Juba (2004-2010). Also, he is a member in Research Council of Sudanese Ministry of Petroleum, Sudanese National Leather Research Center and Consultancy Committee of Sudanese Ministry of Industry.

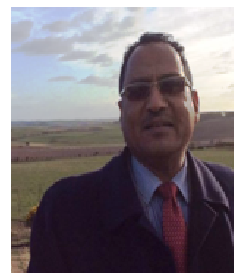

Siddig Eissa Ahmed is the director of Environment and Safety Department, Ministry of Petroleum, Sudan. He received his bachelor in science (first class honors) civil engineering from University of Khartoum, Khartoum, Sudan, in 1981. He received his diploma in irrigation sciences from Katholic University of Leuven, Distinction-Irrigation Centre, Belgium in 1984. He received his master of science in irrigation sciences from Katholic University of Leuven, Distinction-Irrigation Centre, and Belgium in 1985 and He received his $\mathrm{Ph}$. D in environment and water resources engineering from Katholic University of Leuven, Belgium in 1991.

Mr. Ahmed is a member in International Association for Hydraulic Research (IAHR), International Water Research Association (IWRA), International Association for Hydraulic Research (IAHR), Sudan National Committee on Irrigation and Drainage (SNCID), Sudanese Engineering Society (SES), World Water Council (WWC). 